\title{
Twin reversed arterial perfusion in twin pregnancy
}

\section{Thulasi Devi' ${ }^{1}$, Vikas Verma ${ }^{2 *}$}

\begin{abstract}
${ }^{1}$ Department of Obstetrics and Gynaecology, ${ }^{2}$ Department of Radiodiagnosis and Imaging, Military Hospital,
\end{abstract} Amritsar, Punjab, India

Received: 02 August 2020

Revised: 06 September 2020

Accepted: 08 September 2020

\author{
*Correspondence: \\ Dr. Vikas Verma, \\ E-mail: dr.vikasverma20@gmail.com
}

Copyright: (c) the author(s), publisher and licensee Medip Academy. This is an open-access article distributed under the terms of the Creative Commons Attribution Non-Commercial License, which permits unrestricted non-commercial use, distribution, and reproduction in any medium, provided the original work is properly cited.

\begin{abstract}
An interesting case of twin reversed arterial perfusion "TRAP" from a larger apparently normal pump twin with VACTERL abnormality; to smaller structurally abnormal twin in a monoamniotic monochorionic twin pregnancy resulting in fetal demise with subsequent termination of pregnancy. Defect in early embryogenesis leads to such rare multiple presentations.
\end{abstract}

Keywords: TRAP, VACTERL, MAMC twin pregnancy, Twin to twin transfusion syndrome

\section{INTRODUCTION}

Twin reversed arterial perfusion sequence, also called as TRAP sequence, TRAPS, or acardiac twinning refers to a rare complication unique to monochorionic twin pregnancies in which a twin with an absent or rudimentary heart ("acardiac twin") is perfused by its cotwin ("pump twin") via aberrant arterio-arterial anastomoses. The acardiac twin is wholly dependent upon circulatory support from the pump twin, and its upper body and head are often poorly developed, if not altogether absent. Rationale behind presentation of this case is to be aware of this lethal presentation in MAMC twin Pregnancy and possible ablation of aberrant blood supply in very few cases of TTTS (twin to twin transfusion syndrome) with discordance and future role of in utero surgery. This presentation otherwise is invariably lethal. Indications for the ex utero intrapartum therapy (EXIT) procedure have evolved and nowadays in addition to secure the airway, obtain vascular access, administer surfactant and other resuscitation medications, EXIT is used to resect cervical or thoracic masses, for extracorporeal membrane circulation (ECMO) cannulation, as well as to rescue maximum intra-thoracic space for ventilation of the remaining functional lung tissue or in cases in which resuscitation of the neonate may be compromised. EXIT procedure in twin pregnancy has been rarely reported and some doubts have been raised about its strategy and safety in such cases. ${ }^{1}$

\section{CASE REPORT}

A 27 year old $\mathrm{G}_{3} \mathrm{P}_{1} \mathrm{~L}_{1} \mathrm{~A}_{1}$ post $\mathrm{LSCS}$ lady presented to us at POG $11 \mathrm{w}^{+1}$ with MAMC twin Pregnancy. She gave history of OI and TI, non consanginous marriage, with previous history of severe preeclampsia, FGR, severe oligohydramnios and a term CS, a growth restricted female baby with a birth weight of $2.000 \mathrm{~kg}$ with no malformation was delivered. Child is 5 years old and Alive and healthy. She had missed abortion at 45 days of amenorrhoea which was terminated medically. USG and CDS revealed a larger twin with Cardiac activity (Twin 1) and a grossly smaller twin (Twin 2).

There was growth discordance of approximately 4 weeks at POG $14 \mathrm{w}^{+4}$ cardiac activity was absent in recipient twin (Twin 2) and displayed all radiological features of TRAPS with acardiac parabiotic twin; acardius acephalus/acardius chorioangiopagus parasiticus (Figure 1 and Figure 2). This twin had an incompletely formed skeleton, absent 
upper limbs, absence of cranium, (Figure 3) absence of heart or thoracic structures (Figure 4). Abdominal stump had no intraabdominal organs. There were two well developed oedematous lower limbs and cord was single vessel (Figure 1).

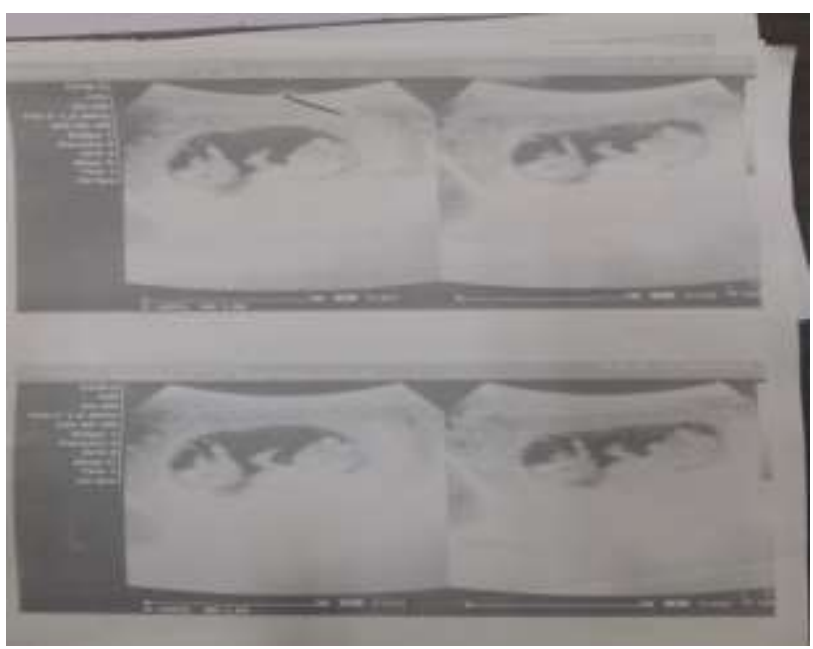

Figure 1: Acardius acephalus/acardius chorioangiopagus parasiticus. Abdominal stump had no intra-abdominal organs. There were two well developed oedematous lower limbs and cord was single vessel.

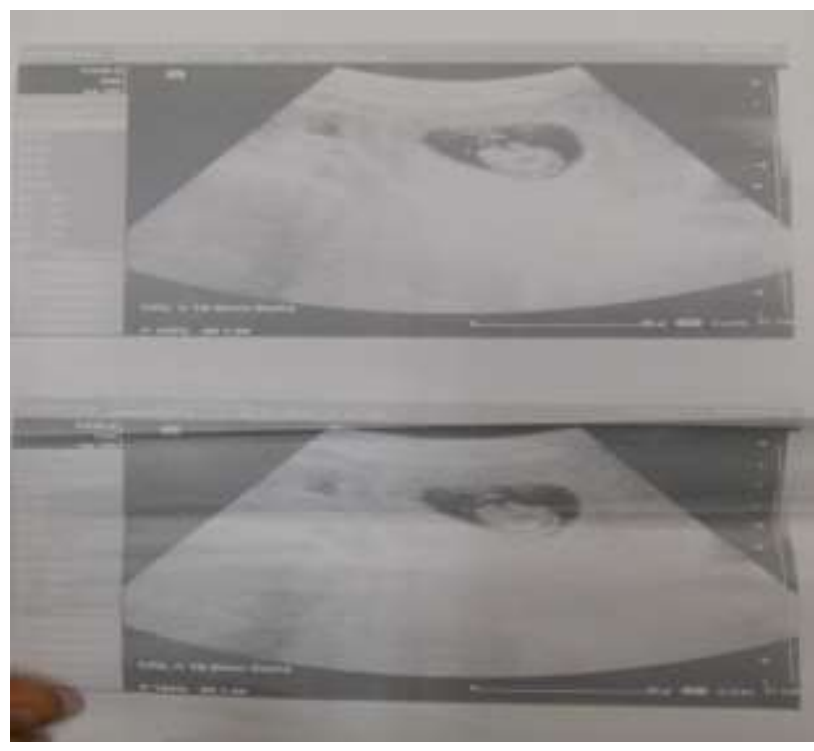

Figure 2: Acardius acephalus/acardius chorioangiopagus parasiticus.

At 18 weeks twin 2 was found to have multiple congenital malformation, hypoplastic heart, vertebral anomalies, and upper limbs were absent and urogenital ridge could not be differentiated. At 20 weeks the surviving twin had an early fetal demise subsequently pregnancy was terminated. Mother did not permit us to take photograph of the abortuses and was unwilling for an autopsy. We can only conclude from the USG findings that VACTERL abnormality was present.

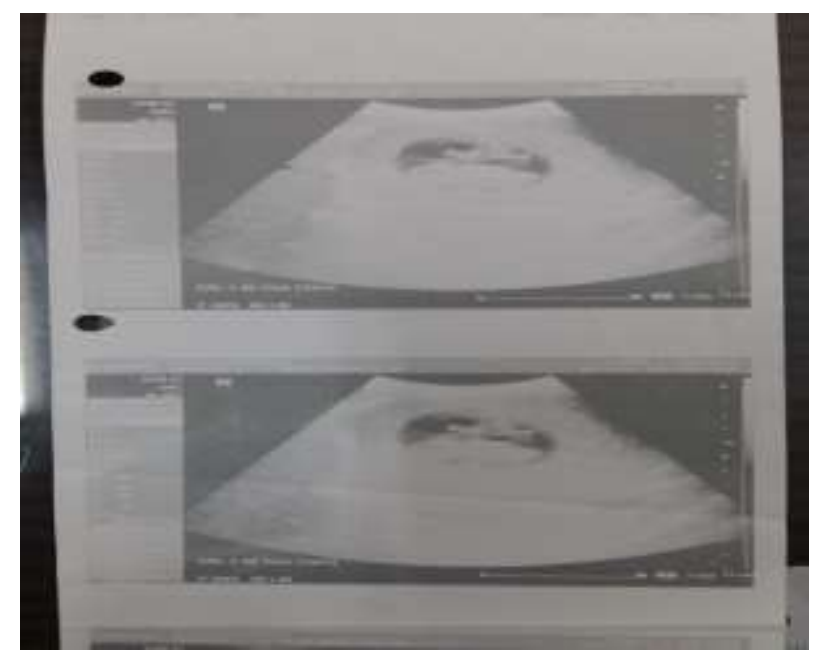

Figure 3: Absent upper limbs and cranium.

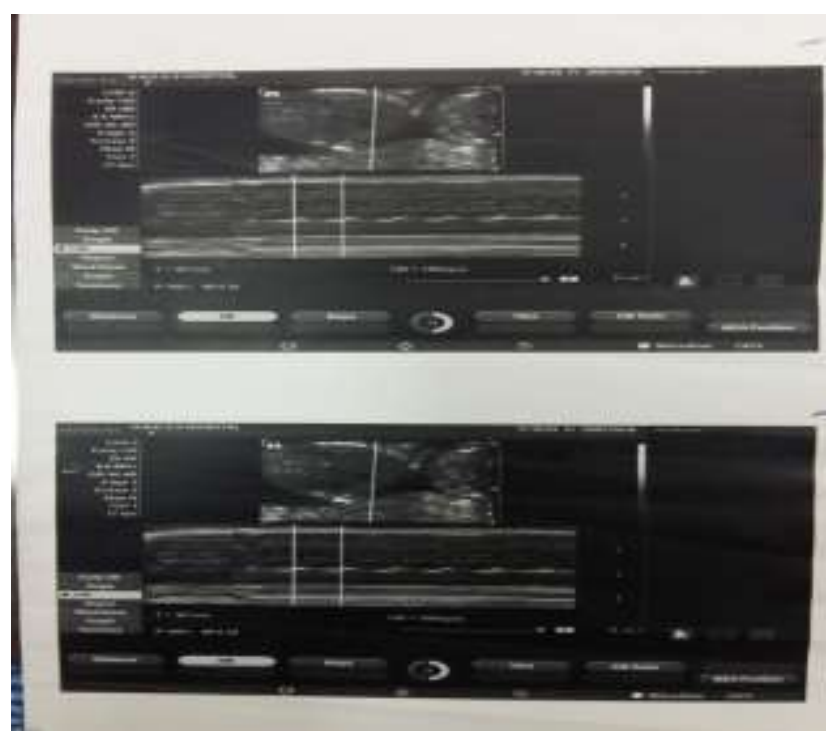

Figure 4: Absence of heart or thoracic structures.

\section{DISCUSSION}

Here we present a MAMC twin pregnancy with TRAPS and VACTERL. It is a severe variant of twin to twin transfusion syndrome (TTTS). The twins' blood systems are connected instead of independent. One twin, called the acardiac twin or TRAP fetus is severely malformed. The heart is missing or deformed, hence the name acardiac, as are the upper structures of the body. The legs may be partially present or missing, and internal structures of the torso are often poorly formed. The other twin is usually normal in appearance. The normal twin, called the pump twin, drives blood through both foetuses. It is called reversed arterial perfusion because in the acardiac twin the blood flows in a reversed direction. Thus, the acardiac twin has no potential for ex utero survival. As a result of the circulatory burden of supporting its acardiac co-twin, the pump twin is at risk of developing heart failure and other complications that may 
lead to preterm birth or death, which are common without intervention. The mortality rate of the pump twin appears to correlate with the size of the acardiac twin. A larger, more developed acardiac twin (with multiple internal organs such as kidneys) is associated with a significant increase in the perinatal mortality of the pump twin. ${ }^{2}$ Other poor prognostic indicators are polyhydramnios and preterm delivery (before 32 weeks' gestation). TRAP may also occur in monochorionic triplet and higher-order multiple gestations. TRAP sequence occurs in $1 \%$ of monochorionic twin pregnancies and in 1 in 35,000 pregnancies overall. ${ }^{3}$ VACTERL association is a non random often lethal congenital malformation in 0.4-1.6 in every 10,000 births. ${ }^{4}$ Here we present a case of ' $V$ ' for vertebral anomalies, ' $\mathrm{A}$ ' imperforate anus, anal atresia, ' $\mathrm{C}$ ' multiple lethal cardiac malformations, 'TE' tracheoesophageal malformations, ' $R$ ' renal malformations and distal urinary defects and ' $L$ ' for limb abnormalities. Combination of all these malformations is lethal. The pathogenesis of TRAP is controversial, with two main pathogenetic hypotheses proposed. ${ }^{5}$ Deep placental anastomoses in early embryogenesis cause malformation of the acardiac twin. The early pressure flow in one twin exceeds that of the other and leads to reversed circulation in the twin who exhibits perfusion.

A primary defect in embryogenesis in one twin leads to failure of cardiac development. The normal twin then perfuses the acardiac twin via artery-artery anastomoses. However, the anastomoses are not responsible for the cardiac anomaly.

Acardiac fetus is clinically divided into two types. Pseudocardiac is the presence of cardiac structures although rudimentary. Halocardia is the absence of cardiac structure development. It is widely classified into four subgroups morphologically. ${ }^{6,7}$ Acardiac acephalic; the fetus has developed pelvis and lower extremities. Head, arms and thoracic organs are absent. This is the most common type with a frequency of $60-75 \%$. Our case is in this group.

Acardiac anceps; body and extremities have developed. Head and face are partially formed. This type consists approximately $20 \%$ of all cases. Acardiac acormus; only the head of the fetus has developed. It is quite rare and consists approximately $10 \%$ of all cases. Acardiac amorphous; the fetus has no identifiable organs. It is as an amorphous tissue mass and it consists approximately 5\% of all cases. This extreme form not only lacks a head and limbs, but also any internal organs, and consists of tissues with blood vessels branching from the umbilical cord. Some may only be stem cell tumors.

The goal of fetal surgery is to interrupt blood supply to the non-viable twin by selective bipolar cord coagulation and radiofrequency ablation (RFA) procedures as treatment options for mothers carrying twins diagnosed with TRAP sequence. This reduces cardiac strain on the pump twin and increases his or her chance of survival. However in presence of lethal malformation termination is the only option.

\section{CONCLUSION}

Monoamniotic monochorionic twin pregnancy requires frequent sonological examination by an experienced fetomaternal medicine specialist or a competent Radiologist for early diagnosis and termination of pregnancy to avoid maternal psychological trauma and morbidity of late termination regarding anticipation of delivery of supposedly normal donor twin. The mortality of the acardiac twin is $100 \%$, and the perinatal mortality of the pump twin is reported to be around $50 \%$. The poor outcome of the pump twin is primarily due to congestive heart failure, cord entanglement or prematurity. ${ }^{8}$

\section{Funding: No funding sources \\ Conflict of interest: None declared \\ Ethical approval: Not required}

\section{REFERENCES}

1. García-Díaz L, de Agustín JC, Ontanilla A, Marenco ML, Pavón A, Losada A. Pregnancy Childbirth. BMC. 2014;14:252.

2. Paek B, Goldberg JD, Albanese CT. Prenatal diagnosis. World J Surg. 2003;27(1):27-37.

3. Healey MG. Acardia: predictive risk factors for the co-twin's survival.Teratology. 1994;50(3):205-13.

4. Gembruch U, Viski S, Bagamery K, Berg C, Germer U.Twin reversed arterial perfusion sequence in twinto-twin transfusion syndrome after the death of the donor co-twin in the second trimester. Ultrasound Obstet Gynecol. 2001;17(2):153-6.

5. Søgaard K, Skibsted L, Brocks V. Review Acardiac twins: pathophysiology, diagnosis, outcome and treatment. Six cases and review of the literature. Fetal Diagn Ther. 1999;14(1):53-9.

6. Wong AE, Sepulveda W. Review Acardiac anomaly: current issues in prenatal assessment and treatment. Prenat Diagn. 2005;25(9):796-806.

7. Hartge DR, Weichert J. Prenatal diagnosis and outcome of multiple pregnancies with reversed arterial perfusion (TRAP-sequence). Arch Gynecol Obstet. 2012;286(1):81-8.

8. Moore TR, Gale S, Benirschke K. Perinatal outcome of forty-nine pregnancies complicated by acardiac twinning. Am J Obstet Gynecol. 1990;163(3):90712.

Cite this article as: Devi LT, Verma V. Twin

reversed arterial perfusion in twin pregnancy. Int $\mathrm{J}$

Reprod Contracept Obstet Gynecol 2020;9:4304-6. 